\title{
The use of discourse markers but and so by native English speakers and Chinese speakers of English
}

\author{
Binmei Liu \\ Nankai University, China
}

Previous studies have found that but and so occur frequently in native and non-native English speakers' speech and that they are easy to acquire by non-native English speakers. The current study compared ideational and pragmatic functions of but and so by native and non-native speakers of English. Data for the study were gathered using individual sociolinguistic interviews with five native English speakers and ten L1 Chinese speakers. The results suggest that even though the Chinese speakers of English acquired the ideational functions of but and so as well as the native English speakers, they underused the pragmatic functions of them. The findings indicate that there is still a gap between native and non-native English speakers in communicative competence in the use of but and so. The present study also suggests that speakers' L1 (Mandarin Chinese) and overall oral proficiency in oral discourse affect their use of but and so.

Keywords: discourse marker, interlanguage, communicative competence, Chinese, oral proficiency, but, so

\section{Introduction}

\subsection{Discourse markers}

"Discourse markers" (DMs) is one of the labels used (e.g. by Jucker and Ziv 1998; Schiffrin 1987; Schourup 1999) for the seemingly empty linguistic items with high frequency in oral discourse, such as well, I mean, like, oh, and $y^{\prime} k n o w .{ }^{1}$ As suggested

1. Another commonly used label for these linguistic items is "pragmatic markers" (PMs) (e.g. by Andersen 2001; Brinton 1996). These two terms reflect the different attitudes of the authors to the question of the uniformity of the class of these expressions (Jucker and Ziv 1998). A general 
by Schiffrin $(1987,328)$, common features of DMs are that: they are "syntactically detachable from a sentence;" "have a range of prosodic contours;" and that they either have to "have no meaning, a vague meaning, or to be reflexive (of the language, of the speaker)". Although DMs are syntactically optional, they are multifunctional. For example, they can help a speaker to organize, hold turns, and mark boundaries in a discourse (Stenström 1994). They can also help a speaker express attitudes such as uncertainty or hesitation, and to signal politeness (Aijmer 2002).

The use of DMs is relevant to second/foreign language (L2) speakers' communicative needs and pragmatic competence. Comparative studies on DM use by L2 speakers and native speakers have boomed in recent years (e.g. Aijmer 2011 on well; Buysse 2012 on so; Müller 2005 on you know, like, so, well). Overuse, underuse, and misuse of L2 DMs have been reported in the literature even with advanced learners of English (e.g. Aijmer 2004), leading to problems of coherence or appropriateness of their speech (Aijmer 2011; Moreno 2001). It is not surprising, therefore, that DMs have remained an area of concern in L2 development of communicative competence. To shed light on learners' problems, it would also be essential to uncover factors which affect L2 DM use.

In response to the above, the present study makes an attempt to examine the use of but and so by native and Chinese speakers of English because their pragmatic use, especially by Chinese speakers of English, is under-studied. The study also focuses on two influential factors (native language and oral proficiency) for the linguistic behavior of Chinese speakers of English. Although the sample size of this study is small, with five native English speakers and ten Chinese speakers of English, the results of this preliminary study provide a possible direction of research on L2 development of communicative competence.

\section{Analytical framework of the study}

Two influential models are used to explain the different functions of DMs in the literature: the relevance-based approach (e.g. Andersen 2001; Blakemore 1988; Jucker 1993) and the discourse coherence model (e.g. Hays 1992; Miracle 1991; Schiffrin 1987). The analysis of DMs within the relevance-based framework is based on Sperber and Wilson's (1986) relevance theory, which is a general theory of human communication based on cognitive principles. The relevance-based approach has successfully analyzed some DMs; however, a different approach may be better suited to explain what they are doing in authentic texts and why the speaker has chosen

agreement is that PM focuses on "the absence of apparent semantic meaning and grammatical category" of the expression (Wei 2011a, 3455). 
one marker rather than another (Aijmer 2002). Schiffrin's (1987) model of discourse coherence consists of five discourse levels: the exchange structure, the action structure, the ideational plane, the participation framework, and the information state. The general idea of this model is that DMs should be described and explained on different planes (levels of discourse). The major flaw of Schiffrin's model is that the planes in the model are not all comparable, well-defined or consistently treated (Redeker 1991).

Since the purpose of this study is to compare ideational/pragmatic use of but and so by L1 and L2 English speakers, the framework of analysis used is Halliday's (1970) functional perspective: ideational, textual, and interpersonal language functions. ${ }^{2}$ There are a number of DM studies which adopt Halliday's (1970) metafunctions for analysis (e.g. Aijmer 2002; Brinton 1996; Buysse 2012). The ideational function of language refers to language serving "for the expression of 'content"" (Halliday 1970, 143), whereas DMs with a textual function create coherence of discourse $^{3}$ (Aijmer 2002). The interpersonal function means that language serves "to establish and maintain social relations" (Halliday 1970, 143) and includes the communicative roles between interlocutors.

The functionalization of DMs from propositional meaning to textual and interpersonal uses involves pragmaticalization (Aijmer 1997). Pragmaticalization involves a movement from the lexical area towards the pragmatic area, and from the sentence level to the macro-textual level (Heine 2013). In terms of output, the evolution of DMs is accompanied by phonetic reduction, syntactic isolation, and pragmatic strengthening (Frank-Job 2006; Hansen 2008). For instance, when like is a preposition, it means "similar to" with propositional meaning, as in "And doing art stuff which I haven't been able to slip in as much either because that takes more set up and clean up time and stuff like that." ${ }^{3}$ When like is used as a pragmatic marker, it can serve a textual function - introducing an example, as in "So we covered like motivation and anxiety and aptitude, and uh well briefly gender, and age, and things like that." In the second example, the italicized like is syntactic optional, with phonetic reduction; it is also propositionally optional. However, it has a discourse organizational meaning.

2. Textual and interpersonal functions are often referred to as "pragmatic functions/use" in order to differentiate from ideational functions in DM studies (e.g. Brinton 1996; Buysse 2012; Müller 2005; Schiffrin 1987).

3. Therefore, the two terms - "textual function" and "discourse function" are often used interchangeably in DM studies (e.g. Aijmer 2002; Buysse 2012; Müller 2005).

4. The two examples in this paragraph are from my data by American participants John and Sue respectively. 
The above meta-functions of DMs will be further analyzed and exemplified for but, so, and their Chinese counterparts in Section 4. The next section will focus on a discussion of the relationship between L2 DM use and communicative competence, together with a review of prior research on but and so.

\section{Literature review}

\subsection{Communicative competence and L2 DMs}

The term "communicative competence" first defined by Hymes (1972) as knowledge of what is possible, feasible, appropriate and actually done has been developed by a number of researchers. The key components of communicative language ability discussed in this section are based on the synthesis of existing models in the literature (Bachman 1990; Bachman and Palmer 2010; Canale and Swain 1980; Hedge 2000). It consists of four components: linguistic competence, pragmatic competence, discourse competence, and strategic competence.

Linguistic competence includes knowledge of pronunciation, vocabulary, morphology, semantics and syntax of the language. Only ideational meaning of DMs is related to linguistic competence but pragmatic use of DMs is not, since PMs are syntactically optional. Without PMs, the language remains grammatically correct.

Pragmatic competence includes two kinds of ability: illocutionary competence, which means knowing how to use language in order to achieve certain communicative goals; and sociolinguistic competence, which is knowledge of the appropriate social conventions of how to use the language in varying situations in a particular culture. Not using DMs in one's speech will not lead to pragmatic failure since DMs are syntactically optional. However, L2 speakers need to master the pragmatic functions of DMs, not only the grammatical forms, for the negotiation of the relationship between speaker and hearer during a conversation (Müller 2005). Furthermore, L2 speakers need to know that DMs are widespread in natural speech (Ostman 1982) and vary in frequency and type according to formality (e.g. Aijmer 2002; Jucker and Smith 1998).

Discourse competence, or textual competence, includes knowledge of joining utterances together to form a coherent text or conversation. Use of DMs in this sense relates to L2 speakers' discourse competence, particularly the ability of language learners to take longer turns, and open and close conversation. For example, language learners need to learn the DMs which signal continuation of discourse such as and, and succession of discourse such as then.

Strategic competence refers to a speaker's ability to exploit communication strategies in an authentic communicative situation. One of the communication 
strategies is using hesitation devices to maintain the conversation. Here, use of DMs relates to L2 speakers' strategic competence as one function of DMs is to serve as a filler or delaying tactic (when searching for appropriate words for a later utterance).

\subsection{Previous studies on 'but' and 'so' by L2 learners}

Although but and so used by L2 English speakers are less studied than some DMs such as like, well, and you know, several scholars have published findings on their use. Hays (1992) found that Japanese speakers of English used and, but, and so at much higher rates than other markers such as because, well, I mean, oh, and you know. He labeled and, but, and so ideational markers because he claimed that these markers related to text not pragmatics. Fung and Carter (2007) compared the use of English DMs by Hong Kong speakers and native British English speakers, and found that Hong Kong learners displayed a frequent use of referential markers ( $a n d, b u t$, because, ok, so, etc.), but a more restricted use of interpersonal markers (yeah, really, say, sort of, I see, you see, well, right, actually, you know, etc.). They suggested that this result reflected that the learners were exposed to traditional grammar-centered pedagogy and hence focused on the semantic meanings of words rather than their pragmatic use in spoken language. Wei (2011b) investigated the use of DMs by university learners of English in China at different proficiency levels (intermediate and advanced) across four task functions. She found that the top four most frequently used DMs were and, but, also and so in the same order by both groups.

Two further studies comprehensively examined the use of so by English learners from Europe. Müller (2005) found that native English speakers used the textual functions of so significantly more often than German speakers of English; however, the interactional functions and the ideational functions of so did not show any significant difference. Buysse's (2012) study showed that Dutch speakers of English used so at a much higher rate than native speakers of English, and that they used interpersonal and textual so at higher rates than native speakers on the whole.

The current study's first research goal is to examine the ideational/pragmatic use of but and so by Chinese speakers of English and native English speakers for three reasons. The literature review shows that but and so occur most frequently in the speech of both native and non-native English speakers (e.g. Fung and Carter 2007; Hays 1992). In addition, use of but by L2 speakers is under-studied in the literature. While the metafunctions of so by L2 learners have been examined by studies such as Buysse (2012), and Müller (2005), none of the previous studies have examined its use by Chinese speakers of English. If participants' first language (L1) is different, the effect of L1 transfer on L2 DMs would be different, and their use of L2 DMs would also be different. 
The current study also sets out to explore how L2 speakers' L1 (Mandarin Chinese) and overall oral proficiency may affect their ideational/pragmatic use of but and so, to better understand the linguistic behavior of L2 speakers. The need of research about L1 influence on the use of L2 DMs has been noticed by several researchers in the field (e.g. Baumgarten and House 2010; Liao 2009; Müller 2004; Wei 2011b), yet it remains an under-studied area in DM studies. Additionally, according to Wei's (2011b) study, L2 speakers' overall oral proficiency level relates to the way L2 DMs are used. However, that study did not examine the relationship of oral proficiency and ideational/pragmatic use of but and so because the goal was to investigate the relationship between L2 speakers' oral proficiency level and L2 DM use across different contextual situations.

The current study therefore addresses the following two research questions:

1. What are the similarities and differences in the ideational and pragmatic use of but and so by native English and Chinese speakers of English?

2. In what ways do L1 and the overall oral proficiency of Chinese speakers of English influence their ideational and pragmatic use of but and so?

\section{Methodology}

\subsection{Participants}

The data of this study are from a larger project which described the use of English DMs by L1 Chinese speakers of English (Liu 2009). The ten L2 English participants involved in that study were graduate students (five male and five female) at an American university, originally from mainland China, and aged between twenty-two and thirty-seven years old (mean $=28.2$ ). The participants have been assigned Chinese pseudonyms (Dong, Feng, Bing, Lian, Xia, Qiu, Peng, Jun, Fang, and Juan) to maintain confidentiality. Each one had received formal English education in China for more than eight years, and had been studying various programs including education, tourism, computer science, linguistics, and biochemical engineering in the U.S. for between three weeks and four years. Their English proficiency was considered advanced because each of the participants scored over 600 in TOEFL (Test of English as a Foreign Language) when the data were collected.

Each participant was asked to take the TSE (Test of Spoken English) at the American university, and they were divided into two groups according to their scores: a higher oral proficiency group, and a lower oral proficiency group. The higher oral proficiency group had a minimum 45 in the TSE (they are Dong, Feng, Lian, Xia, Qiu and Peng) whereas the lower oral proficiency group obtained a 40 
in the TSE (they are Bing, Jun, Fang, Juan). All members of the higher proficiency group except Peng had studied in the U.S. or Canada for over a year when the data were collected, while all those in the lower oral proficiency group, except Bing, had studied in the U.S. for just three weeks.

Five American English native speakers participating in the study (two male and three female) were graduate students at the same university. They studied linguistics, biomedicine and English, and their ages ranged from twenty-four to thirty-five (mean $=29.2$ ). The American participants have been assigned American pseudonyms (John, Davy, Sue, Ann, and Mary).

\subsection{Data collection}

Individual sociolinguistic interviews were conducted to elicit DMs. English interviews were conducted by an American (pseudonym Sherry) who was a graduate student at the same American university. Each participant, native or non-native English speaker, was interviewed for about fifteen minutes. Topics for the interviews were personal in order to elicit an oral narrative register. Interviews with L1 English and L2 English speakers followed the same interview questions (such as weekends, hobbies, travels, favorite sports, favorite teachers, favorite movies, favorite TV programs, and happy experience). Two or three weeks after the English interviews were completed, the ten L1 Chinese speakers were interviewed by the researcher in Mandarin Chinese. The researcher was a graduate student from the same American university, and she also came from mainland China. Each participant was interviewed for about fifteen minutes. The Chinese interviews used the same questions as the English ones.

The data included fifteen interviews in English and ten interviews in Chinese. However, the total number of words in the transcripts included approximately 31,000 English words and 33,500 Chinese words. Indeed, one of the limitations of many DM studies, including the current study, is small sample size. The transcription conventions in the current article follow Müller $(2005,281)$ (see Appendix A). The principles used are simpler than Müller's in that vocal noises, quality, and code switching were not included because they are not related to the research questions under investigation. The next section will sketch the functions of but, so, and their corresponding Chinese expressions that have been attested in the data. 


\section{Discourse marker categorization}

\subsection{Categorizing 'but'}

Schiffrin (1987) states that the primary function of but is its ideational function marking the contrast of ideas, because it is a conjunction. She further suggests that but has a textual function, as a marker of speaker-return - marking claims for the floor and allowing the speaker to return to the point (Schiffrin 1987). Bell (1998) calls this a sequential function of but which signals a return to the main topic or point, and Norrick (2001) applies the speaker-return or shifting function of but in the oral narrative genre.

When it contains an ideational meaning, but is often stressed in the data; however, when serving textual functions, it is never stressed. Analysis of the data in this study reveals but was found to serve one ideational and two textual functions.

The ideational function of but marks the contrast of ideas, as shown in Example (1). When Sue was talking about her favorite professor, but marked the disagreement with the speaker's own previous discourse. It has an ideational meaning, and it is not semantically bleached, although it is syntactically optional.

(1) Sherry: so of your teachers or professors, who is your favorite teacher?

Sue: $\quad$ oh, wow. I think $<\mathrm{X}>$ is my favorite, uh just because like I said like she she gives useful comments. And she's funny.. but sometimes you don't realize she's funny until like, thirty seconds after she's been funny and then you get it. $(\ldots)^{5}$

The first textual function is the use of but as a marker of speaker-return shown in Example (2). John at first said they got on a train and he was sure the train had a themed name, then he said he didn't remember the name. However, he started to describe the train in the following utterance where the underlined but loses its contrastive meaning, and its function is to allow the speaker to return to his original point - the train.

(2) Sherry: Where did you go? What did you do?

John: (...) We got on a train. And.. I'm sure the train has some themed name. I don't remember right now. But the train was kind of an old coach style type thing and it had on the end of cars, the platform where you could stand outside, and.. you know hang precariously off the edge. (...)

5. (...) represents the omitted utterances in that turn by the speaker. Sentences that are too long for inclusion have been omitted. 
The second textual function of but is holding the floor for the speaker. ${ }^{6}$ This function is illustrated in Example (3), in which Mary was telling the interviewer what places she had been to. At the end, Mary gave a summary ("that's the extent of my travel"), filled by but. Here but loses its contrastive meaning, and instead, functions as a floor-holder allowing the speaker to have more time to search for what he/she wants to say next. There is always a pause after this use of but.

(3) Sherry: uh now I'm interested in knowing like your parents are Egyptians, have you traveled a lot?

Mary: No. I wish. (...) Other than that, the only places I've ever traveled were once to California, once to Tennessee, and since we used to live in New Jersey, we've been there a couple of times to visit a family on and off, but.. that's the extent of my travel.

In summary, but was found to serve one ideational function and two textual functions in the data. When serving the ideational function, but marks the contrast of ideas as shown in Example (1), whereas the textual functions serve as a speaker-return marker and a floor-holder for the speaker, illustrated in Examples (2) and (3) respectively.

\subsection{Categorizing danshi 'but'}

The translation equivalent of but has three forms ('dan/danshi/buguo') in the Chinese interview data. They are interchangeable conjunctions, and the most common form in the data is 'danshi'. Fang (2000) suggests that danshi loses its contrastive meaning when used as a DM and it serves two functions: shifting a topic and holding the floor.

In my data, two functions of danshi were found to be used: the ideational function - marking contrast; and a textual function - marking speaker-return. The floor-holding function of danshi was not found to be used by the L1 Chinese speakers. Example (4) illustrates the two functions of danshi when Lian was talking about her travels in China. In the first Question-Answer turn, Lian said she wanted to travel; however, she didn't have enough time. The first underlined danshi marks contrastive ideas serving the ideational function. In the second turn, since the two questions are closely related, Lian used danshi to signal a return to her original point, and this time danshi loses its contrastive meaning.

6. Floor-holding is considered a textual function by some scholars (e.g. Brinton 1996), while an interpersonal function by others (e.g. Aijmer 2002; Buysse 2012).

7. For abbreviations of the Mandarin Chinese gloss when there is no lexical English equivalent, please see Appendix B (Li and Thompson 1981, xxiii). 
$(4)^{7}$ Interviewer: zai guo nei de shihou qu guo shenme difang when country in NOM time go past what place wan ma? play PRT

'When you were in China, which place did you travel to?'

Lian: (..) qishi wo hen xiang wan, danshi mei you actually I very want play but no have shijian. Ranhou Beidaihe qu guo, Tianjin qu guo. time and Beidai River go ExP Tianjin go ExP 'Actually I really wanted to travel, but I didn't have time. And I have been to the Beidai River, been to Tianjin.'

Interviewer: you shenme tebie youyisi de defang?

have what special interesting Nom place

'What is the most interesting place you've been to?'

Lian: danshi zai yinwei wo zai chu guo zhi qian qu but at because I at leave country Nom before go de nage. Jiuzhaigou he nage.. Leshandafo.

NOM that Jiuzhai Valley and that Leshan Giant Buddha Ranhou wo ganjue ting haode. and I feel very good

'But because before I went abroad, I had been to that.. the Jiuzhai Valley, and that.. the Leshan Giant Buddha. And I feel that is very interesting.'

The Chinese DM danshi was therefore found to serve an ideational meaning and a textual function in this study. When having the ideational meaning, danshi marks contrast; and when serving the textual function, it marks speaker-return, with both uses illustrated in Example (4). Furthermore, the data suggest that these functions are similar to the uses of its translation equivalent but except that but was found to have a floor-holding function while danshi was not.

\subsection{Categorizing 'so'}

Schiffrin (1987) suggests that the ideational function of so conveys a meaning of result. She also proposes that "so has a pragmatic use in participation structures - as a marker of potential transition" $(1987,227)$. Müller $(2005,68)$ investigated so on a "textual level" (marking result or consequence, main idea unit marker, summarizing/rewording/giving an example, sequential use, and boundary marker) and an "interactive level" (speech act marker-opinion, question or request, marking implied result, and marker of a transition relevance place). Lam (2010) analyzed 
use of so by Hong Kong speakers of English in different text types. The discourse functions of so in his study were analyzed in textual functions (framing, linking, and consequential), the interpersonal function (responsive), and interactional functions (processing, and turn managing). Buysse (2012) classified so according to three metafunctions: ideational (indicating a result), interpersonal (drawing a conclusion, prompting, and holding the floor), and textual (introducing a summary/a section of the discourse/a new sequence/elaboration, indicating a shift, and marking self-correction).

In this study, the DM so serves one ideational function, four textual functions, and one interpersonal function. The ideational function of so indicates a result, as in Example (5). Davy said he was Jewish and he went to Israel when he was thirteen because it was traditional. The utterance after so ("I went when I was thirteen") is the result of the previous utterance ("it's sort of sort of traditional at that time to go to Israel"). So indicates a result/consequence here, and it can be substituted by "therefore." This use of so is syntactically optional yet semantically unbleached.

(5) Davy: (...) when I was thirteen uh because I'm Jewish, we went to Israel because that's sort of like a, I don't know how to quite say it. It's sort of like, something that every Jewish person is supposed to do at least once in their life time. (...)

Sherry: uh huh.

Davy: It's basically like a coming of age ceremony. It's sort of sort of tradi-

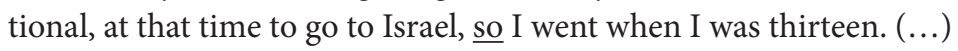

The first textual function of so in the data is to introduce a summary, or to summarize what the speaker has said before. In Example (6), Davy told the interviewer why he chose UF as the graduate school. The first reason was that he wanted to study "Discourse", and the second reason was the issue of financial aid. In the last sentence of his turn, he summarized his descriptions by saying "so those two things sort of were were reasons why I came here."

(6) Sherry: and what made you choose UF?

Davy: uh two reasons, one of which was.. because I I didn't know specifically what I wanted to do. I knew I wanted to be in Discourse. And I saw at that time there were two people here that did that. (...) Also the issue of financial aid. Because I was accepted to, accepted to one of the universities in Texas I think. (...) Uh but they told me that, they wouldn't tell me about the financial aid. Because UF gave me a deadline, you know. (...) So those two things sort of were were reasons why I came here. 
In this function of so, the utterance following so expresses the same propositional idea as the previous discourse (Müller 2005). The speaker does not posit a new claim, but restates the main arguments in more general terms (Buysse 2012). So in this function is more semantically bleached than the resultative so.

The second textual function of $s o$ in the data is to introduce a sequence. It is used to introduce the next event in a series of events, or the next part of the story in a narrative (Müller 2005) or a new step in an explanation (Buysse 2012). This function is illustrated in Example (7) in which Mary was introducing herself to the interviewer.

(7) Sherry: uh so tell me a little bit about yourself.

Mary: about myself uh.. where I'm from or?

Sherry: anything, where you are from, what you are studying.

Mary: ok, well uh ... uh both of my parents are Egyptian, so they are from Egypt. I was born in Canada, and then moved to the States when I was three. And so.. we moved to Florida when I.. was eleven. So I've been here ever since. (...)

Mary said she was born in Canada, and moved to the U.S. when she was three; then her family moved to Florida when she was eleven. The underlined so here was used by the speaker to introduce the next event in her narrative. It is also more semantically bleached than the resultative so.

The third textual function of $s o$ indicates a topic shift. It is used when the speaker comes back after a digression or an explanation to a topic or an opinion mentioned before (Müller 2005). Mary in (8) first said her favorite professor was her mentor, and she started to tell the interviewer that a lot of her courses were multi-subject courses and different professors tried different sub-topics. Then she uses so to return to talk about her favorite professor. In this case, so signals that the speaker shifts back to a higher unit of discourse and used in this way, "either after a brief interruption by or an exchange with the interviewer or after a turn-internal digression" (Buysse 2012, 1772).

(8) Sherry: ok, so tell me do you have a favorite professor?

Mary: I like my professor who is my mentor. Actually, in our courses a lot of courses we had, they were um like multi-subject courses, (...) there're different professors who'd like try different sub-topics. $\underline{\text { So }}$ the professor that I work for.. only gave one lecture in my first year of classes in one of the subgroups of courses that we took. And.. I think he's definitely one of my favorites. (...)

The fourth textual function of $s o$ is floor-holding, and this use of $s o$ is always followed by a pause. Lam $(2010,364)$ suggests that in this function, so is used "as a 
delay strategy and signals that the speaker is undergoing some processing problem and requires extra time". This function is illustrated in Example (9) below.

(9) Sherry: ok. Um, and tell me a little bit about like uh what you're studying here, what classes you've been taking this semester, or this year?

Davy: ok. Well, uh well uh sort of in the Discourse and SLA area, (...) and I took $<\mathrm{X}>$ 's “Technology in Foreign Language Education" class which I also enjoyed. So... And I was taking some independent study hours for this class.

In this example, the underlined so is followed by a pause, but it does not introduce the following segment. The speaker holds on to the floor with so because he needs to have extra time to start a new segment.

The interpersonal function of $s o$ in the data is used to yield the floor, ${ }^{8}$ as in Example (10).

(10) Sherry: you've never watched TV?

John: I haven't.. recently within, you know, I've flipped a couple channels, but decided nothing was on and turned it off. And other than that, not having TV saves me whatever thirty dollars a month and however many hours a week. $\underline{\text { So }}$

Sherry: when you were growing up, did you have a favorite program?

This use of so occurs at the end of a turn, followed by no other words, and always carries a falling or level tone (Buysse 2012). The use of so in this situation is "elliptical" because it "does convey a 'result' meaning even if no result follows" (Schiffrin $1987,223)$. This function "gives an additional cue for the hearer that s/he may take over the floor" (Müller 2005, 85).

In addition to its resultative ideational meaning explained in Example (5), so has multiple pragmatic functions which include four textual functions and one interpersonal function in the data. Illustrated by Examples (6) to (9), the textual functions are listed as introducing a summary, introducing a sequence, indicating a topic shift, and holding the floor for the speaker. The interpersonal function of so is used at the end of a turn, followed by no other words to indicate that the speaker wants to yield the floor to the hearer, as in Example (10).

8. Relinquishing the floor is considered a textual function by Brinton (1996). This use of $\underline{\text { so }}$ is considered an interpersonal one by Buysse (2012) and Müller (2005). 


\subsection{Categorizing suoyi 'so'}

The translation equivalent of so has two interchangeable forms in the Chinese data ('suoyi/suoyishuo'), with 'suoyi' the more common form in the data. Suoyi is a conjunction conveying a result meaning in Chinese. Fang (2000) claims that when becoming semantically bleached, suoyi serves three pragmatic functions: indicating a shift back to the original topic, closing a turn, and a strategy for continuing his/her own turn.

In the current study, suoyi was found to serve the following sub-functions: One ideational function - indicating a result; two textual functions - topic shifting and floor-holding; and one interpersonal function - yielding the floor. In Example (11), Juan said the reason she decided to come to the U.S. was that she felt her job in China was boring. The segment ("I felt my work was not interesting") before suoyi is the reason for the segment after suoyi ("came here"). Suoyi indicates a result/consequence while retaining its semantic meaning.

(11) Interviewer: ni wei shenme hui xuanze dao zhe lai you for what willing choose arrive here come dushu ne? study PRT

'Why did you choose to come to the U.S. and study?' Juan: jiu shi gongzuo de ting mei yisi de.. emphatic be work CsC very not interesting NOM ganjue shang, suoyi jiu lai le. feeling on so just come $\mathrm{PFV}$

'I felt my work was not interesting, so I came here.'

The first textual function of suoyi is indicating a shift back to the original topic which is similar to the topic-shifting function of so. Suoyi is used when the speaker comes back after a digression or an explanation to a topic or an opinion mentioned before, as in Example (12). Bing first said he felt that Americans lived a more real life than Chinese. He then continued talking about how Chinese focused on finding a job, buying a house, etc. and then he made the conclusion that Chinese only focused on the result instead of enjoying the process. After using suoyi, he returned to the original topic, talking about Americans, saying that they knew how to enjoy themselves.

(12) Interviewer: ni lai meiguo zhi hou you mei you shenme you come America Nom after have no have what wenhua chongji?

culture shock

'Have you had any experience of culture shock since you came to America?' 


\begin{tabular}{|c|c|}
\hline Bing: & 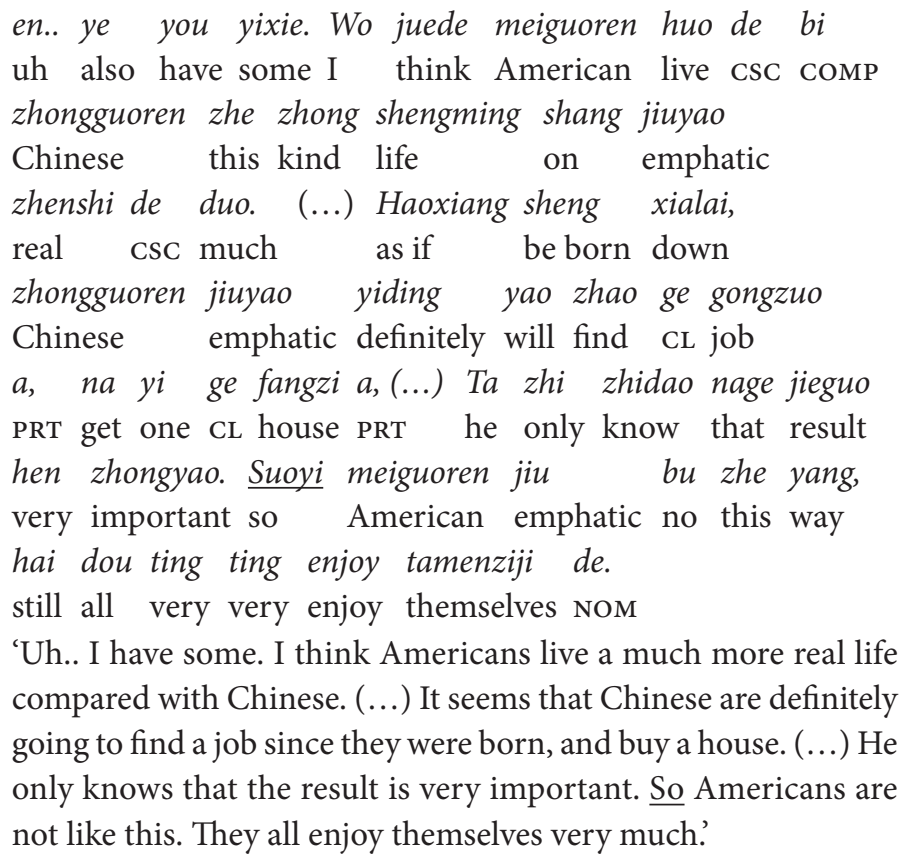 \\
\hline
\end{tabular}

The second textual function of suoyi is holding the floor. Similar to floor-holder use of so, this function of suoyi is usually followed by a pause in the data. In Example (13), Xia talked about why she was busy teaching during the summer. At first, she told the interviewer that she was very tired every day because she had to prepare for two hours before each class. Then she continued her topic, filled by suoyi, and added more reasons why teaching made her so busy, e.g., marking homework. Suoyi here functions as a delay strategy for the speaker to search for her next utterance.

(13) Xia: (...) mei tian suiran wo zhi shang yi ci ke, danshi every day although I only teach one CL class but mei ci ke zhi qian zenme ye dei you liang ge each CL class NOM before whatever too have to have two xiaoshi lai zhunbei. Suoyi ... Erqie liang ge xiaoshi CL hour come prepare so moreover two CL hour zhunbei ba, zhi hou ni hai dei ping juanzi. (...) prepare PRT NOM after you still have to grade paper '(...) Although I teach only one class every day, before each class I have to prepare for at least two hours. $\underline{\text { So }}$... Moreover, besides two hours of preparation, you have to grade after teaching. (...)' 
The interpersonal function of suoyi is yielding the floor, and this use is similar to the interpersonal function of its corresponding English expression so. For example, in (14), Qiu talked about her experience of choosing a major in her university in China. In the first turn she told the interviewer that she didn't choose Japanese as her major, and in the second turn she at first explained that the leaders of her school persuaded her to Choose Japanese and she then accepted this arrangement as her fate, while afterwards she felt terrific about the choice. Suoyi was used at the end of her second turn, followed by no other words, indicating that Qiu was ready to give the floor to the hearer.

(14) Qiu:

(...) wo yiqian mei xiang guo xue riyu. (...) ni I before no think EXP study Japanese you

zhidao ma?

know PRT

'(...) I never thought about studying Japanese as my major. (...) Did you know?'

Interviewer: wei shenme?

for what

'Why?'

Qiu: (...) houlai xuexiao lingdao zuo gongzuo, (...) afterward school leader do work houlai fanzheng ye jiu jieshou le zhege mingyun, afterward anyway too just accept PFV this fate jiu jue le. Suoyi just wonderful CRS so

'(...) Afterward the leaders of my school persuaded me to choose Japanese. (...) Afterward I accepted this fate anyway. It is just wonderful. $\underline{\text { So' }}$

Interviewer: xianzai ne?

now PRT

'What about now?'

The Chinese DM suoyi was found to have: a resultative ideational meaning; two textual functions - topic shifting and floor-holding; and one interpersonal function - yielding the floor, as shown in Examples (11-14). These uses are similar to those of its translation equivalent $s o$ in the data; however, so was also found to serve two more textual functions: introducing a summary; and introducing a sequence. 


\subsection{An overview of qualitative results}

Tables 1 and 2 provide an overview of all DM functions identified for but, so, and their corresponding Chinese expressions dan/danshi/buguo and suoyi/suoyishuo in the data, presented according to the type of discourse relation they mark.

Table 1. Discourse marker functions of but and its corresponding Chinese expressions dan/danshi/buguo

\begin{tabular}{llll}
\hline Type of relation & Discourse marker function & But & Dan/danshi/buguo \\
\hline ideational & marking the contrast of ideas & $\sqrt{ }$ & $\sqrt{ }$ \\
textual & marking speaker-return & $\sqrt{ }$ & $\sqrt{ }$ \\
& holding the floor & $\sqrt{ }$ & \\
\hline
\end{tabular}

Table 1 shows that but was found to serve one ideational function and two textual functions in the data. Its Chinese counterpart was found to serve an ideational meaning and a textual function. The functions of the Chinese counterpart are similar to the uses of but, except that but was found to have a floor-holding function while dan/danshi/buguo was not.

Table 2. Discourse marker functions of so and its corresponding Chinese expressions suoyi/suoyishuo

\begin{tabular}{llll}
\hline Type of relation & Discourse marker function & So & Suoyi/suoyishuo \\
\hline ideational & indicating a result & $\sqrt{ }$ & $\sqrt{ }$ \\
textual & sequencing & $\sqrt{ }$ & \\
& summarizing & $\sqrt{ }$ & \\
& shifting a topic & $\sqrt{ }$ & $\sqrt{ }$ \\
& holding the floor & $\sqrt{ }$ & $\sqrt{ }$ \\
interpersonal & yielding the floor & $\sqrt{ }$ & $\sqrt{ }$ \\
\hline
\end{tabular}

Table 2 indicates that so was found to have one ideational function, four textual functions and one interpersonal function. Its corresponding Chinese expression was found to serve one ideational function, two textual functions and one interpersonal function. The uses of the Chinese counterpart are similar to those of so in the data; however, so was found to serve two more textual functions, i.e. introducing a summary and introducing a sequence. The next section will present the quantitative data by comparing the use of DMs between the L1 and L2 English speakers, and then address how L1 and oral proficiency affect L2 DM use. 


\section{Statistical evidence on the use of discourse markers}

\subsection{Statistical findings by English and Chinese speakers}

The coding of the sub-functions of but and so in each participant's English speech was based on the categorizations in the previous section. The frequency of each function of but and so per person was calculated according to the total tokens per 1,000 words (see Tables 3 and 4).

Table 3. Frequency of different functions of but by native and non-native English speakers (per 1,000 words)

\begin{tabular}{lcllcl}
\hline Speaker & $\begin{array}{l}\text { Marking the } \\
\text { contrast of ideas }\end{array}$ & $\begin{array}{l}\text { Marking } \\
\text { speaker-return }\end{array}$ & $\begin{array}{l}\text { Floor- } \\
\text { holding }\end{array}$ & $\begin{array}{l}\text { Total /1,000 } \\
\text { words }\end{array}$ & $\begin{array}{l}\text { Number of words } \\
\text { in the data }\end{array}$ \\
\hline John & 4.57 & 2.54 & 2.54 & 9.65 & 1,971 \\
Davy & 2.61 & 3.31 & 0 & 5.92 & 1,914 \\
Sue & 5.18 & 4.38 & 1.19 & 10.75 & 2,512 \\
Ann & 3.44 & 3.93 & 0.98 & 8.35 & 2,034 \\
Mary & 4.16 & 2.50 & 2.08 & 8.74 & 2,401 \\
Average & 3.99 & 3.33 & 1.36 & 8.68 & $2,166.4$ \\
Dong & 8.95 & 0.69 & 0 & 9.64 & 1,453 \\
Feng & 7.10 & 4.26 & 0 & 11.36 & 1,409 \\
Bing & 15.95 & 1.45 & 0 & 17.4 & 1,379 \\
Lian & 7.20 & 2.21 & 0 & 9.41 & 1,806 \\
Xia & 1.92 & 1.92 & 0 & 3.84 & 1,039 \\
Qiu & 8.43 & 1.87 & 0 & 10.3 & 1,067 \\
Peng & 5.69 & 0 & 0 & 5.69 & 1,582 \\
Jun & 8.10 & 2.02 & 0 & 10.12 & 988 \\
Fang & 11.94 & 2.65 & 0 & 14.59 & 1,507 \\
Juan & 6.22 & 0.78 & 0 & 7.00 & 1,287 \\
Average & 8.15 & 1.79 & 0 & 9.94 & $1,351.7$ \\
\hline
\end{tabular}

Table 3 shows that both the native and non-native English speakers used the ideational function of but at the highest rates among the sub-functions. The native speakers used the speaker-return function at a similar rate as the ideational function of but (3.99 vs. 3.33 tokens per thousand words per person), while the use of but as a floor holder was the lowest rate (1.36 tokens per thousand words per person) of all the functions. The non-native English speakers used the ideational function at a much higher rate than the speaker-return function of but ( 8.15 vs. 1.79 tokens per thousand words per person) and none of them used the floor-holding function of but.

Table 4 shows that both groups used the ideational function of $s o$ at much higher rates than other functions, and they both used the sequencing function at the second highest rates of all the sub-functions. 
Table 4. Frequency of different functions of so by native and non-native English speakers (per 1,000 words)

\begin{tabular}{lllllllll}
\hline Speaker & $\begin{array}{l}\text { Indicating } \\
\text { a result }\end{array}$ & Sequencing & $\begin{array}{l}\text { Summari- } \\
\text { zing }\end{array}$ & $\begin{array}{l}\text { Shifting } \\
\text { a topic }\end{array}$ & $\begin{array}{l}\text { Floor- } \\
\text { holding }\end{array}$ & $\begin{array}{l}\text { Floor- } \\
\text { yielding }\end{array}$ & $\begin{array}{l}\text { Total/ } \\
1,000 \\
\text { words }\end{array}$ & $\begin{array}{l}\text { Number of } \\
\text { words in } \\
\text { the data }\end{array}$ \\
\hline John & 6.09 & 5.58 & 0 & 1.52 & 2.03 & 2.03 & 17.25 & 1,971 \\
Davy & 3.66 & 0 & 2.61 & 0 & 1.57 & 0 & 7.84 & 1,914 \\
Sue & 6.37 & 1.19 & 1.19 & 0.40 & 1.99 & 0 & 11.14 & 2,512 \\
Ann & 4.92 & 2.95 & 1.47 & 0.49 & 1.48 & 0.98 & 12.29 & 2,034 \\
Mary & 6.66 & 8.33 & 3.33 & 0 & 0.83 & 0 & 19.15 & 2,401 \\
Average & 5.54 & 3.61 & 1.72 & 0.48 & 1.58 & 0.60 & 13.53 & $2,166.4$ \\
Dong & 6.88 & 0 & 1.38 & 0.69 & 0.69 & 0 & 9.64 & 1,453 \\
Feng & 7.10 & 0 & 0 & 0 & 1.42 & 3.55 & 12.07 & 1,409 \\
Bing & 11.60 & 0 & 0 & 0 & 0 & 0 & 11.60 & 1,379 \\
Lian & 8.86 & 3.88 & 0 & 0.55 & 0.55 & 0 & 13.84 & 1,806 \\
Xia & 5.77 & 3.85 & 2.89 & 0 & 0 & 2.89 & 15.40 & 1,039 \\
Qiu & 5.62 & 0 & 0 & 0 & 0.94 & 0 & 6.56 & 1,067 \\
Peng & 6.32 & 0.63 & 0 & 0 & 0.63 & 0 & 7.58 & 1,582 \\
Jun & 2.02 & 0 & 0 & 1.01 & 1.01 & 0 & 4.04 & 988 \\
Fang & 7.30 & 0 & 0 & 0 & 0 & 0 & 7.30 & 1,507 \\
Juan & 4.66 & 0 & 0.78 & 0 & 0.78 & 0 & 6.22 & 1,287 \\
Average & 6.61 & $\mathbf{0 . 8 4}$ & $\mathbf{0 . 5 1}$ & $\mathbf{0 . 2 3}$ & $\mathbf{0 . 6 0}$ & $\mathbf{0 . 6 4}$ & $\mathbf{9 . 4 3}$ & $\mathbf{1 , 3 5 1 . 7}$ \\
\hline & & & & & & & & \\
\hline
\end{tabular}

Coding of the sub-functions of their Chinese corresponding expressions in each L1 Chinese speaker's Chinese data was also based on the categorizations in the previous section. The frequency of each function of dan/danshi/buguo 'but' and suoyi/suoyishuo 'so' per person was calculated according to the total tokens per 1,000 words (see Tables 5 and 6).

Independent-Samples $\mathrm{T}$ tests were run in order to see if there is a significant difference in the uses of but and so by the native English speakers and the Chinese speakers of English; the results are presented in Table 7.

The results in Table 7 show that the Chinese speakers of English used the ideational function of but more often than the native English speakers at a significant level $(p<.05)$. However, the native speakers used the two textual functions of but significantly more frequently than the non-native English speakers. The Chinese speakers of English used but a total number of times at a slightly higher rate than the native speakers (9.94 vs. 8.68 tokens per thousand words per person), but not at a significant level. We can also see that the native English speakers used so at a higher rate than the non-native speakers ( 13.53 vs. 9.43 tokens per thousand words per person), but not at a significant level. As for the sub-functions, the native speakers used the ideational function of $s o$ at a slightly lower rate than the non-native speakers (5.54 vs. 6.61 tokens per thousand words per person). They used the 
Table 5. Frequency of different functions of dan/danshi/buguo 'but' by L1 Chinese speakers (per 1,000 words)

\begin{tabular}{llllll}
\hline Speaker & $\begin{array}{l}\text { Marking the } \\
\text { contrast of } \\
\text { ideas }\end{array}$ & $\begin{array}{l}\text { Marking } \\
\text { speaker-return }\end{array}$ & Floor-holding & $\begin{array}{l}\text { Total } \\
/ \mathbf{1 0 0 0} \\
\text { words }\end{array}$ & $\begin{array}{l}\text { Number of } \\
\text { words in the } \\
\text { data }\end{array}$ \\
\hline Dong & 4.50 & 0 & 0 & 4.50 & 2,664 \\
Feng & 1.17 & 0 & 0 & 1.17 & 2,572 \\
Bing & 7.01 & 0.35 & 0 & 7.36 & 2,852 \\
Lian & 6.46 & 0.65 & 0 & 7.11 & 3,095 \\
Xia & 3.01 & 0.50 & 0 & 3.51 & 3,994 \\
Qiu & 3.18 & 0 & 0 & 3.18 & 3,144 \\
Peng & 2.34 & 0.39 & 0 & 2.73 & 2,568 \\
Jun & 2.98 & 0.33 & 0 & 3.31 & 3,018 \\
Fang & 5.15 & 0 & 0 & 5.15 & 2,137 \\
Juan & 2.97 & 0.25 & 0 & 3.22 & 4,044 \\
Average & 3.88 & 0.25 & 0 & 4.13 & $3,008.8$ \\
\hline
\end{tabular}

Table 6. Frequency of different functions of suoyi/suoyishuo ("so") by L1 Chinese speakers (per 1,000 words)

\begin{tabular}{lllllllll}
\hline Speaker & $\begin{array}{l}\text { Indicating } \\
\text { a result }\end{array}$ & $\begin{array}{l}\text { Sequencing } \\
\text { zing }\end{array}$ & $\begin{array}{l}\text { Summari- } \\
\text { zhifting } \\
\text { a topic }\end{array}$ & $\begin{array}{l}\text { Floor- } \\
\text { holding }\end{array}$ & $\begin{array}{l}\text { Floor- } \\
\text { yielding }\end{array}$ & $\begin{array}{l}\text { Total } \\
/ 1000 \\
\text { words }\end{array}$ & $\begin{array}{l}\text { Number of } \\
\text { words in } \\
\text { the data }\end{array}$ \\
\hline Dong & 1.50 & 0 & 0 & 0 & 0.38 & 0 & 1.88 & 2,664 \\
Feng & 0.39 & 0 & 0 & 0 & 0 & 0 & 0.39 & 2,572 \\
Bing & 1.05 & 0 & 0 & 0.35 & 0 & 0 & 1.40 & 2,852 \\
Lian & 1.94 & 0 & 0 & 0 & 0.65 & 0 & 2.59 & 3,095 \\
Xia & 3.25 & 0 & 0 & 0 & 0.75 & 0 & 4.00 & 3,994 \\
Qiu & 4.77 & 0 & 0 & 0 & 0 & 0.32 & 5.09 & 3,144 \\
Peng & 0 & 0 & 0 & 0 & 0 & 0 & 0 & 2,568 \\
Jun & 0.66 & 0 & 0 & 0 & 0.33 & 0.33 & 1.32 & 3,018 \\
Fang & 1.87 & 0 & 0 & 0 & 0 & 0 & 1.87 & 2,137 \\
Juan & 1.73 & 0 & 0 & 0 & 0.49 & 0 & 2.22 & 4,044 \\
Average & $\mathbf{1 . 7 2}$ & $\mathbf{0}$ & $\mathbf{0}$ & $\mathbf{0 . 0 3}$ & $\mathbf{0 . 2 6}$ & $\mathbf{0 . 0 6}$ & $\mathbf{2 . 0 7}$ & $3,008.8$ \\
\hline
\end{tabular}

sequencing function (3.61 vs. 0.84 tokens per thousand words per person) and the shifting function ( 0.48 vs. 0.23 tokens per thousand words per person) at higher rates than the Chinese speakers of English, but not at a significant level. They used the summarizing function more frequently than the non-native English speakers (1.72 vs. 0.51 tokens per thousand words per person), and the difference between them neared significance $(p=.059)$. Both the native and non-native speakers used the interpersonal function 'floor-yielding' at similarly low rates ( 0.60 vs. 0.64 tokens 
per thousand words per person). Finally, the native speakers used the floor-holding function ( 1.58 vs. 0.60 tokens per thousand words per person) more frequently than the non-native speakers at a significant level $(p<.05)$.

Table 7. Use of but and so by native and non-native English speakers (per 1,000 words) (an asterisk indicates statistical significance for the function)

\begin{tabular}{|c|c|c|c|c|c|c|c|}
\hline \multirow[t]{2}{*}{ Individual function } & \multicolumn{2}{|c|}{$\begin{array}{l}\text { Native } \\
\text { English } \\
\text { speakers }\end{array}$} & \multicolumn{2}{|c|}{$\begin{array}{l}\text { Non-native }(n=10) \\
\text { English } \\
\text { speakers }\end{array}$} & \multirow[t]{2}{*}{$\mathrm{t}$} & \multirow[t]{2}{*}{$\mathbf{d f}^{9}$} & \multirow[t]{2}{*}{$\begin{array}{l}\text { Sig. (2 } \\
\text { tailed) }\end{array}$} \\
\hline & Mean & $\begin{array}{l}\text { Std. } \\
\text { deviation }\end{array}$ & Mean & $\begin{array}{l}\text { Std. } \\
\text { deviation }\end{array}$ & & & \\
\hline \multicolumn{8}{|l|}{ but } \\
\hline $\begin{array}{l}\text { marking the } \\
\text { contrast of ideas }\end{array}$ & 3.99 & 1.00 & 8.15 & 3.75 & -2.396 & 13 & ${ }^{\star} .032$ \\
\hline $\begin{array}{l}\text { marking } \\
\text { speaker-return }\end{array}$ & 3.33 & 0.83 & 1.79 & 1.19 & 2.593 & 13 & ${ }^{*} .022$ \\
\hline floor-holding & 1.36 & 0.99 & 0 & 0 & 3.062 & 4.000 & ${ }^{\star} .038$ \\
\hline Total & 8.68 & & 9.94 & & -.659 & 13 & .521 \\
\hline \multicolumn{8}{|l|}{ so } \\
\hline indicating a result & 5.54 & 1.80 & 6.61 & 4.00 & -.866 & 13 & .392 \\
\hline sequencing & 3.61 & 3.37 & 0.84 & 1.61 & 1.734 & 4.934 & .143 \\
\hline summarizing & 1.72 & 1.29 & 0.51 & 0.96 & .404 & 13 & .059 \\
\hline shifting a topic & 0.48 & 0.62 & 0.23 & 0.38 & 1.004 & 13 & .334 \\
\hline floor-holding & 1.58 & 0.49 & 0.60 & 0.48 & 3.703 & 13 & ${ }^{\star} .003$ \\
\hline floor-yielding & 0.60 & 0.90 & 0.64 & 1.37 & -.062 & 13 & .952 \\
\hline Total & 13.53 & 4.61 & 9.43 & 3.69 & 1.878 & 13 & .083 \\
\hline
\end{tabular}

Independent-Samples $\mathrm{T}$ tests were also run to see if there is a significant difference in but and so between the higher oral proficiency group and the lower oral proficiency group of the Chinese speakers of English. Table 8 presents the results.

Table 8 shows that the higher oral proficiency group used the textual and interpersonal functions of but and so at higher rates than the lower oral proficiency group, and the lower oral proficiency group used the ideational but at a much higher rate than the higher oral proficiency group. Furthermore, the higher oral proficiency group used the total number of so at an obviously higher rate than the lower oral proficiency group.

9. When equal variances are assumed, $\mathrm{df}$ is 13 ; when equal variances are not assumed, $\mathrm{df}$ is not 13. 
Table 8. Use of but and so by the higher oral proficiency group and lower oral proficiency group (per 1,000 words) (an asterisk indicates statistical significance for the function)

\begin{tabular}{|c|c|c|c|c|c|c|c|}
\hline \multirow[t]{2}{*}{$\begin{array}{l}\text { Individual } \\
\text { function }\end{array}$} & \multicolumn{2}{|c|}{$\begin{array}{l}\text { Higher oral }(n=6) \\
\text { proficiency } \\
\text { group }\end{array}$} & \multicolumn{2}{|c|}{$\begin{array}{l}\text { Lower oral }(n=4) \\
\text { proficiency } \\
\text { group }\end{array}$} & \multirow[t]{2}{*}{$\mathrm{t}$} & \multirow[t]{2}{*}{$\mathbf{d f} \mathbf{f}^{10}$} & \multirow[t]{2}{*}{$\begin{array}{l}\text { Sig. }(2 \\
\text { tailed })\end{array}$} \\
\hline & Mean & $\begin{array}{l}\text { Std. } \\
\text { deviation }\end{array}$ & Mean & $\begin{array}{l}\text { Std. } \\
\text { deviation }\end{array}$ & & & \\
\hline \multicolumn{8}{|l|}{ but } \\
\hline $\begin{array}{l}\text { marking the } \\
\text { contrast of ideas }\end{array}$ & 6.55 & 2.54 & 10.55 & 4.31 & -1.870 & 8 & .098 \\
\hline $\begin{array}{l}\text { marking } \\
\text { speaker-return }\end{array}$ & 1.83 & 1.46 & 1.73 & 0.80 & .123 & 8 & .905 \\
\hline floor-holding & 0 & 0 & 0 & 0 & $\begin{array}{l}\text { cannot be } \\
\text { computed }\end{array}$ & $\begin{array}{l}\text { cannot be } \\
\text { computed }\end{array}$ & $\begin{array}{l}\text { cannot be } \\
\text { computed }\end{array}$ \\
\hline Total & 8.37 & 2.93 & 12.28 & 4.62 & -1.653 & 8 & .137 \\
\hline \multicolumn{8}{|l|}{ so } \\
\hline indicating a result & 6.76 & 1.18 & 6.40 & 4.09 & .173 & 3.339 & .873 \\
\hline sequencing & 1.39 & 1.93 & 0 & 0 & 1.768 & 5.000 & .137 \\
\hline summarizing & .71 & 1.20 & .20 & 0.39 & .817 & 8 & .437 \\
\hline shifting a topic & .21 & 0.32 & .25 & 0.51 & -1.77 & 8 & .864 \\
\hline floor-holding & .71 & 0.47 & .45 & 0.53 & .814 & 8 & .439 \\
\hline floor-yielding & 1.07 & 1.68 & 0 & 0 & 1.569 & 5.000 & .177 \\
\hline Total & 10.85 & 3.51 & 7.30 & 3.18 & 1.626 & 8 & .143 \\
\hline
\end{tabular}

\subsection{Discussion}

Hays (1992) found that but and so were the second and third most frequently used DMs by Japanese speakers of English. Fung and Carter (2007) found that Hong Kong speakers of English used but more frequently than native speakers of English. Wei (2011b) also found that but and so were among the most frequently used DMs by both intermediate and advanced Chinese learners of English. However, none of these studies compared but/so in ideational and pragmatic functions. The results of this study suggest that Chinese speakers of English only used the ideational function of but and so at a higher rate than native English speakers, but not the pragmatic functions which is inconsistent with the findings of Fung and Carter (2007). The Chinese speakers of English underused almost all of the pragmatic functions of the two DMs (except the floor-yielding function of so) compared with the native English speakers, indicating that the non-native English speakers had not acquired

10. When equal variances are assumed, $\mathrm{df}$ is 8 ; when equal variances are not assumed, $\mathrm{df}$ is not 8 . 
the pragmatic functions of but and so to the same degree as the native speakers even though they were advanced learners of English. Among the non-native English speakers, there is still a gap in discourse competence and pragmatic competence in the use of but and so, especially in the three sub-functions of the two DMs.

None of the Chinese speakers of English were found to use the floor-holding use of $b u t$, while four out of the five native English speakers used it. Furthermore, the sequencing function of $s o$ is the second most frequently used function of $s o$, and four out of the five native English speakers were found to use it. However, only three out of the ten Chinese speakers of English were found to use this function. In addition, the summarizing function of so is the third most frequently used function of so by the native English speakers, with four out of the five native English speakers found to use it. By contrast, only three out of the ten Chinese speakers of English were found to use this function.

With regard to the research question of influence of L1, there are three pieces of evidence showing the influence of L1 on the use of but and so. Tables 5 and 6 show that the L1 Chinese speakers used the ideational functions of danshi 'but' and suoyi 'so' at higher rates than their pragmatic functions. This result is consistent with the use pattern of their corresponding English DMs - but and so. The frequent use of the ideational but/so could be because the Chinese speakers of English transferred the ideational functions of danshi 'but' and suoyi 'so' to the ideational uses of but and so. Especially in the use of the ideational but, the Chinese speakers of English used it significantly more frequently than the native English speakers. Specifically, Bing used both the ideational but and the ideational danshi 'but' at the highest rates (see Tables 3 and 5) which is perhaps due to L1 transfer. Furthermore, none of the L1 Chinese speakers in the study used the floor-holding function of but or danshi 'but' (see Tables 3 and 5). The non-native English speakers' lack of use of floor-holding but might be due to their lack of use in their L1. Additionally, the sequencing function and summarizing function of so were the second and third most frequently used functions by the native English speakers respectively. However, not many Chinese speakers of English were able to use these two functions in the data, and Table 6 shows that none of the Chinese speakers used suoyi 'so' for sequencing or summarizing either. Therefore, the lack of use of sequencing and summarizing suoyi 'so' in Chinese might lead to their low tokens of sequencing and summarizing so in English.

To sum up, the results of this study suggest that the ideational functions of but/ so are more easily transferred from L1, perhaps because their corresponding Chinese equivalents are translatable. On the other hand, the pragmatic functions of but/so/ danshi 'but'/suoyi 'so' are semantically bleached; therefore, no translation equivalents are available for Chinese speakers of English even when transfer is needed.

In response to the research question of influence of oral proficiency, the DM use patterns between the two oral proficiency groups are quite similar to the patterns between the native and non-native English speakers. Moreover, the finding that the higher oral proficiency group had a more frequent use of the textual functions of but 
and so coincides with the nature of DMs in that one of their functions is to serve as a hesitation device in colloquial speech (Brinton 1996), thus they can be indicators of L2 fluency (He and Xu 2003; Tsai and Chu 2015). When L2 speakers use DMs for hesitation or for linking words and phrases, speech sounds faster and more fluent than when they pause or use er, and erm too often. Meanwhile, the result that the higher oral proficiency group in the present study used the interpersonal function of $s o$ at a higher rate indicates that more proficient L2 speakers may be more capable of managing the social relationship with the addressee, which is consistent with the findings in Wei (2011a).

\section{Conclusion}

The current study has found that Chinese speakers of English underuse the pragmatic functions of but and so and overuse the ideational but compared with native English speakers, which is inconsistent with the findings in previous studies (e.g. Hays 1992) that $b u t$ and so were easy to acquire by non-native English speakers. The results could be partly due to L1 transfer because the ideational functions of their corresponding Chinese equivalents are translatable, while the pragmatic functions are not.

Despite its small sample size, the current study suggests that even though L2 speakers appear to use the total tokens of some DMs such as but and so as much as L1 English speakers, this is actually not the case. It is necessary to identify different sub-functions of an individual DM when examining its use by native and non-native speakers in order to see a full picture of their DM use.

Pedagogically speaking, this study lends strong support to enhancing L2 speakers' communicative competence on the pragmatic level. To fulfill the purpose, students in EFL/ESL classrooms can be given explicit instruction on differences between ideational and pragmatic functions of DMs through authentic speech samples. Moreover, a comparative analysis of DMs by native and non-native speakers in authentic situations can be highlighted in teaching so that students can have more opportunities to critically reflect on their own DM use and communicative experiences using native models. More studies need to be conducted to explore how DMs can be taught in speaking classes to empower L2 speakers to become communicatively competent (Fung 2011; Jones and Carter 2014; Wei 2011b; Yoshimi 2001).

\section{Acknowledgements}

I am grateful to the journal's editors and anonymous reviewers for their insightful comments and suggestions. I thank Dr. Wayne Tucker from College of Foreign Languages of Nankai University for checking the quality of English of this paper. 


\section{References}

Aijmer, Karin. 1997. “I think: An English Modal Particle.” In Modality in Germanic Languages: Historical and Comparative Perspective, ed. by Toril Swan, and Olaf Jansen Westvik, 1-47. Berlin: Mouton de Gruyter. doi:10.1515/9783110889932.1

Aijmer, Karin. 2002. English Discourse Particles: Evidence from a Corpus. Amsterdam/ Philadelphia: John Benjamins. doi:10.1075/scl.10

Aijmer, Karin. 2004. “Pragmatic Markers in Spoken Interlanguage.” Nordic Journal of English Studies 3: 173-190.

Aijmer, Karin. 2011. "Well I'm not sure I think... The Use of Well by Non-Native Speakers." International Journal of Corpus Linguistics 16: 231-254. doi:10.1075/ijcl.16.2.04aij

Andersen, Gisle. 2001. Pragmatic Markers and Sociolinguistic Variation: A Relevance-theoretic Approach to the Language of Adolescents. Amsterdam/ Philadelphia: John Benjamins. doi: $10.1075 /$ pbns.84

Bachman, Lyle F. 1990. Fundamental Considerations in Language Testing. Oxford: Oxford University Press.

Bachman, Lyle F., and Adrian S. Palmer. 2010. Language Assessment in Practice. Oxford: Oxford University Press.

Baumgarten, Nicole, and Juliane House. 2010. "I think and I don't know in English as Lingua Franca and Native English Discourse." Journal of Pragmatics 42: 1184-1200.

doi:10.1016/j.pragma.2009.09.018

Bell, David M. 1998. “Cancellative Discourse Markers: A Core/periphery Approach.” Pragmatics 8: 515-541. doi:10.1075/prag.8.4.03bel

Blakemore, Diane. 1988. “'So' as a Constraint on Relevance." In Mental Representations: The Interface Between Language and Reality, ed. by Ruth M. Kempson, 183-195. Cambridge: Cambridge University Press.

Brinton, Laurel J. 1996. Pragmatic Markers in English: Grammaticalization and Discourse Functions. Berlin/New York: Mouton de Gruyter. doi:10.1515/9783110907582

Buysse, Lieven. 2012. "So as a Multifunctional Discourse Marker in Native and Learner Speech." Journal of Pragmatics 44: 1764-1782. doi:10.1016/j.pragma.2012.08.012

Canale, Michael, and Merrill Swain. 1980. “Theoretical Bases of Communicative Approaches to Second Language Teaching and Testing.” Applied Linguistics 1: 1-47. doi:10.1093/applin/1.1.1

Fang, Mei. 2000. "Ziran kouyu zhong ruohua lianci de huayu biaoji gongneng [Reduced conjunctions as discourse markers]". Zhongguo Yuwen [Chinese language] 5: 459-470.

Frank-Job, Barbara. 2006. “A Dynamic - Interactional Approach to Discourse Markers." In Approaches to Discourse Particles, ed. by Kerstin Fischer, 395-413. Amsterdam: Elsevier.

Fung, Loretta. 2011. "Discourse Markers in the ESL Classroom: A Survey of Teachers' Attitudes." Asian EFL Journal 13: 199-248.

Fung, Loretta, and Ronald Carter. 2007. "Discourse Markers and Spoken English: Native and Learner Use in Pedagogic Settings." Applied Linguistics 28: 410-439. doi:10.1093/applin/ammo30

Halliday, Michael Alexander Kirkwood. 1970. "Language Structure and Language Function.” In New Horizons in Linguistics, ed. by John Lyons, 140-165. Harmondsworth: Penguin.

Hansen, Maj-Britt Mosegaard. 2008. Particles at the Semantics/Pragmatics Interface: Synchronic and Diachronic Issues. Bingley: Emerald Group.

Hays, Paul R. 1992. “Discourse Markers and L2 Acquisition.” Papers in Applied Linguistics-Michigan 7: 24-34. 
He, Anping, and Manfei Xu. 2003. “Zhongguo daxuesheng yingyu kouyu small words de yanjiu [Small words in Chinese EFL learners' spoken English]." Waiyu Jiaoxue Yu Yanjiu [Foreign language teaching and research] 35: 446-452.

Hedge, Tricia. 2000. Teaching and Learning in the Language Classroom. Oxford: Oxford University Press.

Heine, Bernd. 2013. "On Discourse Markers: Grammaticalization, Pragmaticalization, or Something Else?” Linguistics 51: 1205-1247. doi:10.1515/ling-2013-0048

Hymes, Dell. 1972. “On Communicative Competence." In Sociolinguistics, ed. by John B. Pride, and Janet Holmes, 269-293. Harmondsworth: Penguin.

Jones, Christian, and Ronald Carter. 2014. “Teaching Spoken Discourse Markers Explicitly: A Comparison of III and PPP.” International Journal of English Studies 14: 37-54. doi: 10.6018/ijes/14/1/161001

Jucker, Andreas H. 1993. “The Discourse Marker Well: A Relevance-Theoretical Account.” Journal of Pragmatics 19: 435-452. doi:10.1016/0378-2166(93)90004-9

Jucker, Andreas H., and Sara W. Smith. 1998. “And People Just you Know like 'Wow': Discourse Markers as Negotiating Strategies." In Discourse Markers: Descriptions and Theory, ed. by Andreas H. Jucker, and Yael Ziv, 171-201. Amsterdam/Philadelphia: John Benjamins. doi: 10.1075/pbns.57.10juc

Jucker, Andreas H., and Yael Ziv (eds). 1998. Discourse Markers: Descriptions and Theory. Amsterdam/Philadelphia: John Benjamins. doi:10.1075/pbns.57

Lam, Phoenix W. Y. 2010. "The Effect of Text Type on the Use of So as a Discourse Particle." Discourse Studies 11: 353-372. doi:10.1177/1461445609102448

Li, Charles. N., and Sandra A. Thompson. 1981. Mandarin Chinese: A Functional Reference Grammar. Berkeley/Los Angeles/London: University of California Press.

Liao, Silvie. 2009. "Variation in the Use of Discourse Markers by Chinese Teaching Assistants in the US." Journal of Pragmatics 41: 1313-1328. doi:10.1016/j.pragma.2008.09.026

Liu, Binmei. 2009. Discourse Marker Use by L1 Chinese EFL Speakers. The University of Florida Ph.D. Thesis.

Miracle, W. Charles. 1991. Discourse Markers in Mandarin Chinese. The Ohio State University Ph.D. Thesis.

Moreno, Ángela Eugenia Iglesias. 2001. "Native-Speaker - Non-Native Speaker Interaction: The Use of Discourse Markers." ELLA 2: 129-142.

Müller, Simore. 2004. “'Well you Know that Type of Person': Functions of Well in the Speech of American and German Students." Journal of Pragmatics 36: 1157-1182. doi:10.1016/j.pragma.2004.01.008

Müller, Simore. 2005. Discourse Markers in Native and Non-native English Discourse. Amsterdam/ Philadelphia: John Benjamins. doi:10.1075/pbns.138

Norrick, Neal R. 2001. "Discourse Markers in Oral Narrative." Journal of pragmatics 33: 49-878. doi: 10.1016/S0378-2166(01)80032-1

Ostman, Jan Ola. 1982. "The Symbiotic Relationship between Pragmatic Particles and Impromptu Speech." In Impromptu Speech: A Symposium, ed. by Nils Enkvist, 147-177. Abo, Finland: Abo Akademi.

Redeker, Gisela. 1991. “Linguistic Markers of Discourse Structure.” Linguistics 29: 1139-1172.

Schiffrin, Deborah. 1987. Discourse Markers. Cambridge: Cambridge University Press. doi: $10.1017 / C B O 9780511611841$ 
Schourup, Lawrence. 1999. “Tutorial Overview: Discourse Markers.” Lingua 107: 227-265. doi:10.1016/Soo24-3841(96)90026-1

Sperber, Dan, and Deirdre Wilson. 1986. Relevance: Communication and Cognition. Oxford: Blackwell.

Stenström, Anna-Brita. 1994. An Introduction to Spoken Interaction. London and New York: Longman.

Tsai, Pei-Shu, and Wo-Hsin Chu. 2015. "The Use of Discourse Markers among Mandarin Chinese Teachers, and Chinese as a Second Language and Chinese as a Foreign Language Learners." Applied Linguistics: amv057. doi:10.1093/applin/amv057

Wei, Ming. 2011a. "Investigating the Oral Proficiency of English Learners in China: A Comparative Study of the Use of Pragmatic Markers." Journal of Pragmatics 43: 3455-3472. doi:10.1016/j.pragma.2011.07.014

Wei, Ming. 2011b. "A Comparative Study of the Oral Proficiency of Chinese Learners of English across Task Functions: A Discourse Marker Perspective." Foreign Language Annals 44: 674-691. doi:10.1111/j.1944-9720.2011.01156.x

Yoshimi, Dina Rudolph. 2001. “Explicit Instruction and JFL Learners' Use of Interactional Discourse Markers." In Pragmatics in Language Teaching, ed. by Kenneth R. Rose, and Gabriele Kasper, 223-244. Cambridge: Cambridge University Press. doi:10.1017/CBO9781139524797.016

\section{Appendix A. Transcription symbols}

\section{Units}

Word

Truncated word \{space $\}$

\section{Speakers}

Speaker identity/turn start Speech overlap

Transitional continuity

Final

Continuing

Appeal

$$
\text { ? }
$$

\section{Pauses}

Long, medium

Short

\section{Transcriber's perspective}

Uncertain hearing

$<\mathrm{XX}>$

Indecipherable syllable

$\mathrm{X}$

\section{Non-word notations}

Filled pause

Agreement (backchannel)

Negation uh, um

mhm, uh huh nhn 
Appendix B.

$\begin{array}{ll}\text { CL } & \text { classifier } \\ \text { COMP } & \text { comparative } \\ \text { CRS } & \text { currently relevant state (le) } \\ \text { CSC } & \text { complex stative construction (de) } \\ \text { EXP } & \text { experiential aspect (-guo) } \\ \text { GEN } & \text { genitive (-de) } \\ \text { NOM } & \text { nominalizer (de) } \\ \text { PFV } & \text { perfective aspect (-le) } \\ \text { PL } & \text { plural } \\ \text { PRT } & \text { particle }\end{array}$

\section{Author's address}

Binmei Liu

English Department

Nankai University

Weijin Road \# 94

Tianjin 300071

China

binmeiliu@yahoo.com 